\title{
NO. 168
}

MARCH

2021

\section{KEY POINTS}

- In Sri Lanka, the impact on employment immediately after the coronavirus disease (COVID-19) outbreak was cushioned by significantly reduced working hours instead of layoffs.

- Technical and vocational education and training (TVET) graduates from tourism and hospitality courses or TVET graduates working as self-employed were the hardest hit.

- The quality of TVET was drastically reduced because of the difficulty in providing practical training online, and delivering lectures under limited access to the internet and devices.

- Students enrolled in TVET courses managed to review lecture notes and submit assignments through lowtech solutions like social media (e.g., WhatsApp).

- Quality of learning could be improved significantly through financial support to students for internet access as well as acquisition of laptops and smartphones as medium-tech solutions. High-tech solutions such as simulation and virtual laboratories could also be explored. In addition to instructor training, changing mindsets toward blended learning will be important as further courses of action.

ISBN 978-92-9262-730-0 (print) ISBN 978-92-9262-731-7 (electronic) ISSN 2071-7202 (print) ISSN 2218-2675 (electronic) Publication Stock No. BRF210081-2 DOI: http://dx.doi.org/10.22617/BRF210081-2

\section{COVID-19 Impact on Technical and Vocational Education and Training in Sri Lanka}

\section{Ryotaro Hayashi \\ Social Sector Economist \\ Human and Social Development \\ Division, South Asia Department \\ Asian Development Bank}

Halgamage Don Sudarshana

Anojan Jayasundara

Senior Social Economist Officer

(Gender)

Sri Lanka Resident Mission

Asian Development Bank

\section{Marito Garcia \\ Fellow \\ Darden Business School \\ Center for Global Initiatives \\ University of Virginia}

Amila Balasuriya

Senior Research Professional

Centre for Poverty Analysis

Tatsuya Hirokawa
University of Tokyo

\section{INTRODUCTION AND OBJECTIVE}

Sri Lanka President Gotabaya Rajapaksa declared 2021-2030 as the "Decade of Skills Development", which has the ambitious goal of reducing the population of unskilled labor to 10\%. This is in line with the national development policy framework "Vistas of Prosperity and Splendour" (Government of Sri Lanka 2020a). Technical and vocational education and training (TVET) will play an instrumental role to realize the "Decade of Skills Development". After the parliamentary elections in August 2020, the government strengthened institutional arrangements by integrating responsibility for TVET into the Ministry of Education so that all education subsectors (general education, skills development, and higher education) could be holistically geared toward skills development to meet the fast-changing demands of the fourth industrial revolution.

However, the coronavirus disease (COVID-19) pandemic has posed significant challenges to education and employment, including TVET. Current TVET instructors and students have struggled with online and distance education, which was introduced abruptly under

* This brief was peer reviewed by Paul Vandenberg, senior economist, Economic Research and Regional Cooperation Department, Asian Development Bank (ADB); and Fook Yen Chong, senior social sector specialist (skills development), Southeast Asia Department, ADB. The authors are grateful for the review and inputs from Utsav Kumar, senior country economist, Sri Lanka Resident Mission, ADB; Sangun Choi, social sector specialist, South Asia Department, ADB.

The authors also appreciate topjobs.lk for sharing their data. 
the new norm of social distancing. TVET institutions experienced the significant challenge of providing hands-on practical training using tools and machines through online training. The turbulence in Sri Lanka's job market created by COVID-19 (Hayashi and Matsuda 2020) will have a negative impact on the employment outcomes of TVET graduates.

This brief presents evidence on the impact of COVID-19 on TVET in Sri Lanka using two primary datasets. First, this brief uses TVET graduate tracer studies conducted in 2016, 2019, and November 2020 by the Asian Development Bank (ADB). In the 2016 wave, 1,996 people who had graduated from TVET institutions between 1 October 2014 and 30 September 2015 were traced (ADB 2018). In 2019, TVET graduates from 2017 were tracked, for a sample size of 2,023. The third wave tracked graduates from the 2018 cohort and numbered 2,085. These tracer studies were conducted at least 1 year after graduation. Second, quantitative online surveys (conducted July-August 2020) and qualitative interviews (conducted October 2020) of TVET institutions and students in Sri Lanka were undertaken by ADB under the guidance of the Presidential Task Force on Education Affairs and the Ministry of Education.

\section{COVID-19 IMPACT ON LABOR MARKET}

Sri Lanka managed to keep the number of COVID-19 cases relatively low until September 2020, but economic contraction was unavoidable. COVID-19 dealt a significant blow to the economy, which is projected to contract by $5.5 \%$ in 2020 (ADB 2020b).

A resurgence of COVID-19 cases from the fourth quarter (Q) of 2020 has caused economic uncertainties for 2021 especially for exports and tourism (ADB 2020a). The effects of the economic downturn that began after the Easter Sunday attacks in April 2019 when gross domestic product fell to 2.3\% in 2019 from 3\%-5\% during 2014-2018, are still lingering. In Sri Lanka, the first positive case of COVID-19 was identified on 27 January 2020 from a foreign tourist. Positive cases were found among Sri Lankan nationals from early March 2020. The government declared public holidays to contain the spread of the virus and a lockdown-styled curfew was in place from 20 March to 11 May 2020, although some parts of the country lifted the curfew earlier than 11 May 2020. All the education and training institutions were closed beginning March 2020. They gradually reopened from June 2020, but a second wave of outbreaks started in October 2020 and a partial lockdown was again imposed in high-risk areas.

Compared to the same months in 2019 , online job postings dropped significantly during the first two waves of COVID-19 in 2020 (Figure 1). The number of online job postings had declined sharply from March 2020, especially for the tourism and hospitality sector, but gradually improved by September 2020. It again declined significantly when the second wave began in October 2020. While the number of COVID-19 cases grew rapidly in Q4 2020, the number of online postings began to recover in December 2020. This recovery may not signal additional employment if the online job advertisement is to replace the jobs lost during the first wave, or if more employers use online job posting as a means of recruiting employees.

Labor demand remained weak for tourism and hospitality from the start of the pandemic in March 2020. This is because of the international travel restrictions due to COVID-19 although international tourists started to visit Sri Lanka from the end of December 2020 on a pilot basis. Under the government's mediumterm Skills Sector Development Program 2014-2020, four industries were prioritized: (i) building and construction, (ii) tourism and hospitality, (iii) metal and light engineering, and (iv) information and communication technology (ICT). Except for the tourism and hospitality sector, the priority industries showed resilience to this shock compared to the overall average. Engineering-related online postings recovered quickly after the first wave. During the second wave, postings for information technology recovered strongly.

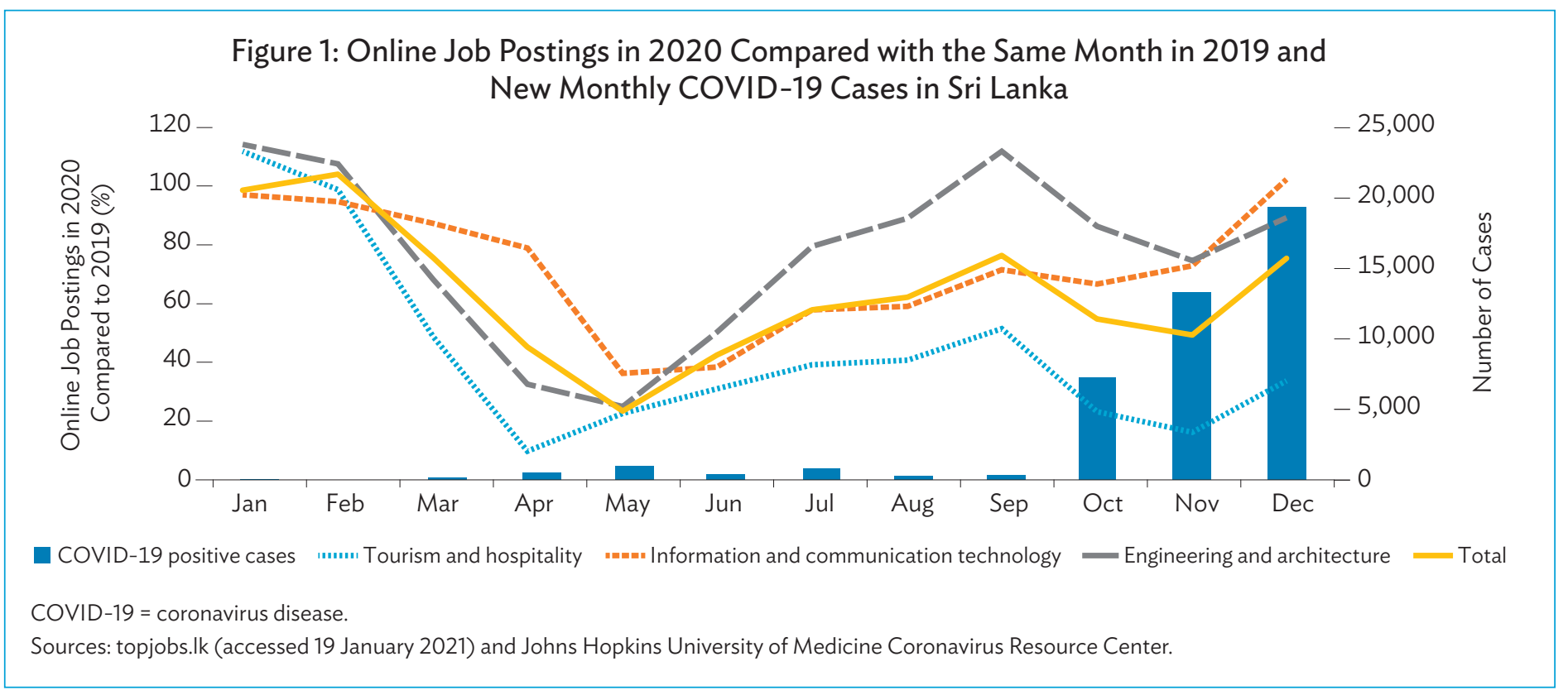


Globally, lost weekly working hours in 2020 is estimated to be 8.8\% relative to Q4 2019 (ILO 2021). The reduction in working hours and employment loss are estimated to reduce labor income by $8.3 \%$ in 2020 . The main coping strategy for firms, however, is not necessarily to lay off workers (Apedo-Amah et al. 2020); instead, the most popular measure is to grant leave, followed by reducing working hours and wages. Laying off workers seems to be the last option, with women and young workers being the most vulnerable. The women were more affected than men because women's share in accommodation and food services is usually higher. Employers may not have advertised the new recruitment positions to retain existing workers; and young workers may have lost opportunities for employment, or delayed their participation in the labor force. For 2020, the predicted mean sales reduction in Sri Lanka due to COVID-19 is 59\% compared to weeks from the peak of the COVID-19 shock (Apedo-Amah et al. 2020). The unemployment rate rose to $5.4 \%$ (male: $4.1 \%$, female: $8.2 \%$ ) in Q2 2020 (Government of Sri Lanka 2020b), a level last seen at the end of civil conflict in 2009. Among all age groups, youth unemployment (15-24 years) was the highest at $27.7 \%$ (male: $24.1 \%$, female: $34.4 \%$ ). Women, particularly those with education, struggled to find jobs. This is not peculiar to the COVID-19 situation and has been observed in previous surveys. This is most likely because many educated women had taken up arts, which did not necessarily provide skills needed for the industry.

\section{ONLINE TECHNICAL AND VOCATIONAL EDUCATION AND TRAINING}

COVID-19 forced students to continue their education and training online, a learning approach that is not completely new to the TVET sector in Sri Lanka. The Tertiary and Vocational Education Commission (TVEC) deployed ICT in an effort to achieve a sustainable system of distance learning for postsecondary education through the Distance Education Modernization Project in 2003 (ADB 2016). However, the project focus was more on higher education institutions than TVET, and distance learning adoption was limited in the absence of sound track records and proper accreditation of distance learning courses. Prior to COVID-19, only $36 \%$ of TVET institutions provided distance learning.

The use of online platforms for delivering training accelerated during the pandemic. Online offerings are important in mitigating the risk of COVID-19 transmission, and TVEC has facilitated the open access to e-resources during the pandemic. In addition, while TVET institutions resumed face-to-face training in June 2020, some institutions remained closed due to the partial lockdown and still continue to rely on online technologies. The expectation that TVET could continue during the pandemic was high, although only one in five households owned either a desktop or laptop in Sri Lanka (Government of Sri Lanka 2019). TVEC developed a road map for distance learning in Sri Lanka's TVET sector, and a series of measures were considered for the future. Further policy planning and implementation will benefit from the evidence clarifying the challenges during the COVID-19 pandemic.

\section{DESCRIPTION OF DATA}

After the start of the pandemic, we collected two primary datasets to assess its impact on TVET in Sri Lanka. The first dataset is a tracer study conducted in November 2020 that tracked 2,085 TVET graduates from the 2018 cohort. This tracer study data was compared with two earlier waves of TVET graduates from 2016 and 2019 to understand the changes. Seven public TVET institutions participated in the three waves of tracer studies:

(i) Ceylon German Technical Training Institute (CGTTI),

(ii) Department of Technical Education and Training (DTET),

(iii) National Apprentice and Industrial Training Authority (NAITA),

(iv) National Youth Service Council (NYSC),

(v) Ocean University of Sri Lanka (OUSL),

(vi) University of Vocational Technology (UNIVOTEC), and

(vii) Vocational Training Authority (VTA).

Around 2,000 TVET graduates were contacted through computerassisted telephone interviews for each wave. The 2020 wave also included some graduates from university colleges.

The second primary dataset provides information about the delivery and use of online TVET by current students and instructors. Mixed methods were used for data collection and analysis. First, two quantitative online surveys covering TVET institutions and students (trainees) were conducted on 21 July-18 August 2020. Next, seven qualitative interviews were conducted in October 2020 (through voice calls using WhatsApp) with TVET instructors and trainees in four public TVET institutions (i.e., NAITA, DTET, UNIVOTEC, and VTA).

The quantitative assessment collected 201 responses from TVET institutions and 1,085 responses from trainees. The respondents from institutions were largely instructors, teachers, and lecturers. ${ }^{1}$ The respondents to the two online quantitative surveys included almost all major public TVET institutions in Sri Lanka. ${ }^{2}$ Compared to a similar online survey for tertiary education in Hayashi et al. (2020), the number of respondents in the two quantitative online surveys was quite limited because of poor reach. Nearly half of the respondents were from NAITA, which compromised the representativeness of the dataset. The quantitative surveys were conducted online but participants might already have certain strong positive views about online training because of their relatively good internet access.

Other respondents include director general, deputy director general, director, assistant director, principal, deputy principal, manager, administrative officer, and course coordinator.

2 Six public TVET institutions participated in the institutional online survey: (i) NAITA, (ii) DTET, (iii) OUSL, (iv) UNIVOTEC, (v) University College, and (vi) VTA. The trainee online survey also covered these six institutions as well as National Youth Corps and NYSC. 


\section{FINDINGS FROM THE TRACER STUDIES}

\section{COVID-19 Impact on Employment}

The job placement rate dropped by 2.8 percentage points from $51.0 \%$ in 2019 to $48.2 \%$ in 2020 (Table 1). The placement rate was calculated as the number of currently employed graduates divided by the total sample. The decline is driven by graduates who took TVET courses not certified under the National Vocational Qualification framework. The decline in employed TVET graduates is also evident from Figure 2. Interestingly, TVET graduates started to leave their jobs a few months before the pandemic began because of the timing of the new courses (starting in January 2020). However, the number of TVET graduates who were forced into unemployment hiked after the pandemic was declared in March 2020. There is a strong gender impact, as shown by the significant decline among male non-national vocational qualification graduates. In addition, among the unemployed job seekers as of November 2020, one third mentioned that COVID-19 forced them to look for a job. However, the decline in job placement rate started even before COVID-19 as the figure in 2019 was $51.0 \%$, which was lower than $54.5 \%$ in 2016 (Table 1).

In contrast, the employment rate improved slightly from $70.3 \%$ in 2019 to $70.8 \%$ in 2020 due to a drop in labor force participation by TVET graduates. The employment rate is calculated as the number of currently employed graduates divided by the graduates in the labor force. The graduates outside the labor force are mostly students, and COVID-19 might have prompted students, especially women, to continue in education and training rather than enter the labor force. Moreover, while some graduates continued to look for jobs online, by phone, and through social networks, others stopped looking for jobs due to the reduced number of job postings and health concerns around COVID-19. By sector, tourism and hospitality was significantly affected, as the employment rate declined from $76.6 \%$ in 2019 to $58.9 \%$ in 2020 . As noted earlier, tourism and hospitality had already been hit by the Easter Sunday attacks in April 2019. Other priority industries such as building and construction, ICT, and metal and light engineering were also negatively affected in 2019 due to shocks.

\section{Table 1: Job Placement Rate of Graduates}

(\%)

\begin{tabular}{|c|c|c|c|c|c|c|c|c|c|}
\hline \multirow[b]{2}{*}{ NVQ/Non-NVQ } & \multicolumn{3}{|c|}{2016} & \multicolumn{3}{|c|}{2019} & \multicolumn{3}{|c|}{2020} \\
\hline & Male & Female & All & Male & Female & All & Male & Female & All \\
\hline Non-NVQ & 61.0 & 36.7 & 50.4 & 45.1 & 30.7 & 34.1 & 21.4 & 24.4 & 23.6 \\
\hline NVQ & 67.1 & 41.6 & 56.2 & 63.1 & 44.5 & 53.5 & 60.1 & 41.7 & 51.6 \\
\hline Overall & 65.3 & 40.2 & 54.5 & 61.4 & 42.0 & 51.0 & 57.5 & 38.6 & 48.2 \\
\hline
\end{tabular}

$N V Q=$ national vocational qualification .

Note: Details on the 2016 technical and vocational education and training graduate tracer study are available in ADB. 2018. Tracer Study Sri Lanka: Public Training Institutions in 2016. Manila.

Source: Asian Development Bank estimates.

\section{Figure 2: Number of Job Leavers in Four Priority Sectors}

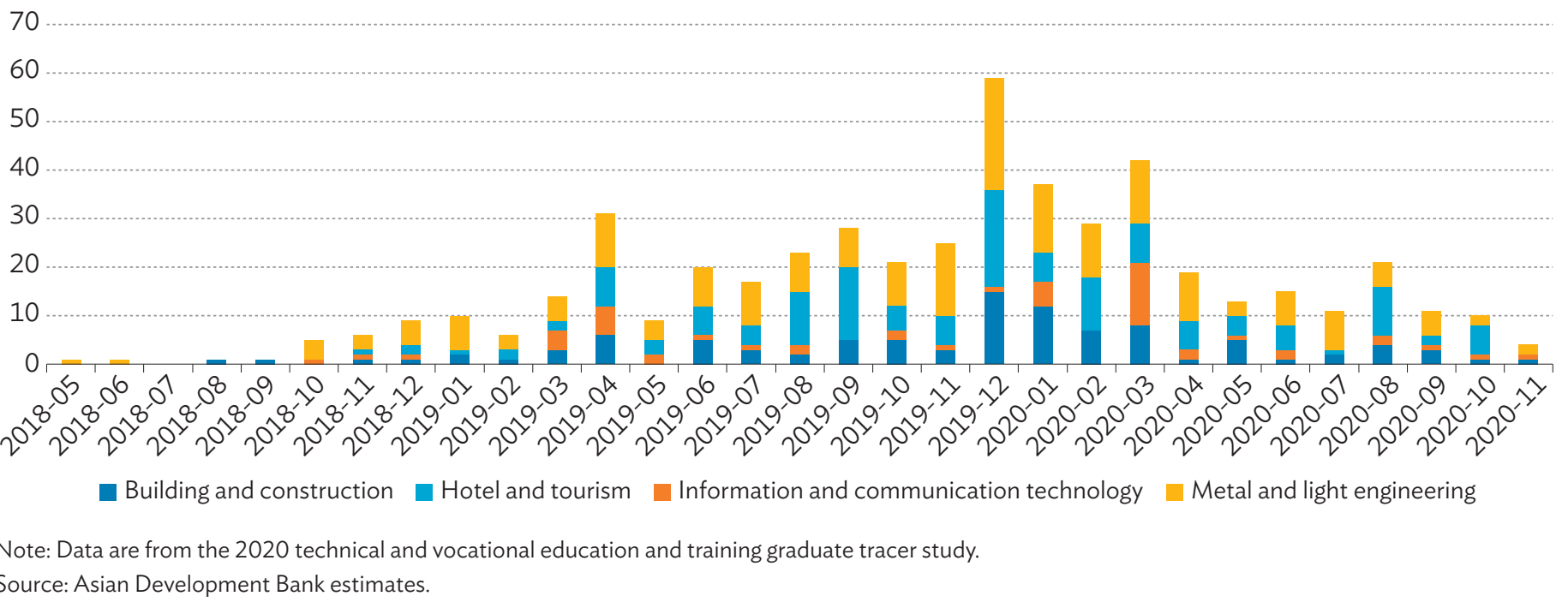




\section{COVID-19 Impact on Working Hours}

The immediate COVID-19 impact was a reduction in working hours. Figure 3 shows weekly working hours among TVET graduates (i) before COVID-19 (before March 2020), (ii) during the first wave of COVID-19 (March-June 2020), and (iii) during the second wave of COVID-19 (November 2020). During the first wave, most TVET graduates worked less than 5 hours or had no working hours. This is contrary to the other two time periods, when many TVET graduates worked 40-55 hours per week.

\section{COVID-19 Impact on Income}

Self-employed graduates experienced a decline in median income from 25,000 Sri Lanka rupees (SLRs) per month before the pandemic to SLRs15,000 as of November 2020. This is a $40 \%$ decline compared to pre-COVID-19, and is by far larger than the $8.3 \%$ global income decline (ILO 2021). The monthly salary distribution for self-employed graduates showed salary declines after the pandemic (Figure 4). Despite these challenges in self-employment, COVID-19 seems to have spurred entrepreneurship for some TVET graduates who lost their jobs. In particular, female entrepreneurs who had taken beautician and tailoring courses increased in 2020.

Wage employees experienced less of a decrease, with median monthly wages decreasing from SLRs34,000 to SLRs30,000 (12\% decline). For wage workers, the distribution shifted toward the left but only marginally. The peak of the distribution was clearly around SLRs35,000 before COVID-19 but the peak plateaued between SLRs20,000 and SLRs35,000 during the pandemic. More than half of employed TVET graduates attributed the reduction in income as a COVID-19 impact since many of them could not go to the office between March and June 2020. At the time of the November 2020

Figure 3: Distribution of Working Hours per Week Before and After Declaration of the COVID-19 Pandemic

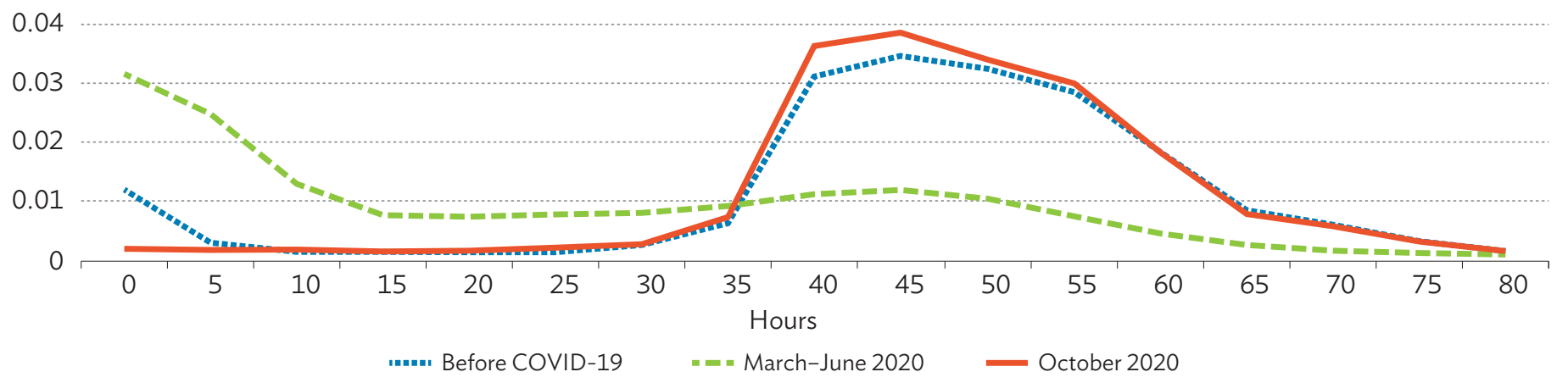

COVID-19 = coronavirus disease.

Notes: This distribution uses kernel density estimation, which is a nonparametric way to estimate the probability density function of working hours per week. Data are from the 2020 technical and vocational education and training graduate tracer study.

Source: Asian Development Bank estimates.

Figure 4: Distribution of Monthly Salary (SLRs '000) of Employed and Self-Employed Graduates

Employed TVET Graduates

0.00003

0.000025

0.00002

0.000015

0.00001

0.000005

0

051015202530354045505560657075
Monthly Income
Self-Employed TVET Graduates

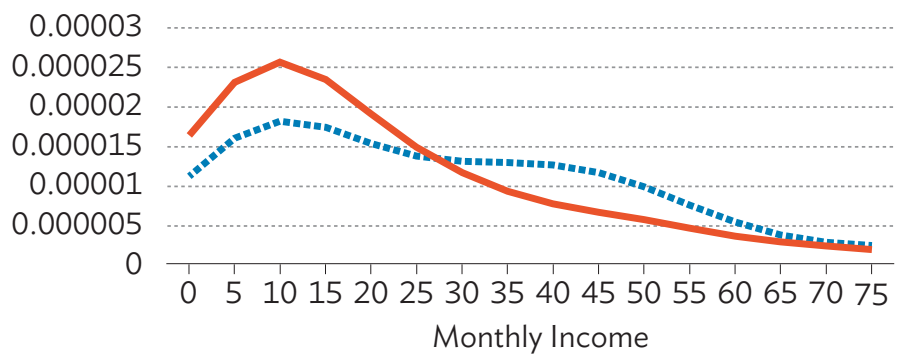

November 2020

COVID-19 = coronavirus disease, SLRs = Sri Lanka rupees, TVET = technical and vocational education and training.

Notes: This distribution uses kernel density estimation, which is a nonparametric way to estimate the probability density function of working hours per week.

Data are from the 2020 TVET graduate tracer study.

Source: Asian Development Bank estimates. 
tracer study, some employed TVET graduates working in the tourism and hospitality industry were still at home, expecting that employers would contact them when the situation improves.

\section{FINDINGS FROM SURVEYS ON ONLINE COURSES}

\section{Online Course Take-Up During the Pandemic}

The online survey conducted on 21 July-18 August 2020 showed that between $60 \%$ and $70 \%$ of major TVET courses continued during the pandemic. The survey showed $92 \%$ of institutions provided at least one online TVET course, and 93\% of student respondents attended online learning mostly through low-tech solutions using social media (Table 2). Among course offerings, $82 \%$ of the TVET institutions could deliver online TVET for information technology courses. However, other major courses, such as automobile mechanics, beautician, building and construction, electrical engineering, electronics and telecommunication, and tourism and hospitality are within the range of $60 \%$ and $70 \%$ (Table 3).

The two quantitative online surveys show that student participation for online TVET is around 90\% across genders, general education certificate level, and income background, but this may be due to the limited sample size where students with good internet access were more likely to participate in the survey. The seven qualitative interviews did point out the risks of exclusion from the survey and online TVET delivery for those who cannot afford to pay internet or mobile data costs, or purchase smartphones and laptops.

While self-selection in the online survey participation remains a concern, the above figures are a significant achievement considering that only $36 \%$ of TVET institutions had provided distance learning before COVID-19. Many respondents agreed that online offerings were useful to continue their training during the pandemic. Some participants in the seven qualitative interviews, however, criticized the use of online training because they said it resulted in duplication, as lectures had to be recapped after face-to-face training resumed. The recap was necessary because some students could not access their courses online while the institutions were closed. Online TVET requires suitable curriculum, learning content, and assessment criteria but there was no evidence that such a transformation had taken place.

Not surprisingly, practical training could not be delivered online, as practical training in many disciplines requires the use of tools, machines, and facilities. Some subjects such as information technology could conduct practical training online through medium-tech solutions if students had good internet access and personal computers. However, for most TVET subjects, such as automobile mechanics and electrical engineering, it was very challenging to provide practical training without specialized tools and equipment. There was also no evidence that hightech solutions such as virtual reality and augmented reality are used for practical TVET during the pandemic. Even if high-tech facilities were provided for online practical TVET, instructors
Table 2: Key Online Survey Results, July-August 2020

\begin{tabular}{lcc} 
& $\begin{array}{c}\text { Yes } \\
(\%)\end{array}$ & $\begin{array}{c}\text { Sample } \\
\text { Size }\end{array}$ \\
\hline $\begin{array}{l}\text { Online TVET Institutional Survey } \\
\text { During COVID-19, remote learning } \\
\text { was provided }\end{array}$ & 92 & 199 \\
\hline $\begin{array}{l}\text { Before COVID-19, remote learning } \\
\text { was provided }\end{array}$ & 36 & 195 \\
\hline $\begin{array}{l}\text { Knowledge and experience in online } \\
\text { learning by instructors }\end{array}$ & 86 & 154 \\
\hline $\begin{array}{l}\text { Online Student Survey } \\
\text { Attended remote learning }\end{array}$ & 93 & 1,079 \\
\hline
\end{tabular}

COVID-19 = coronavirus disease, TVET = technical and vocational education and training

Source: Asian Development Bank estimates.

\section{Table 3: Proportion of Courses Delivered Online During the COVID-19 Pandemic}

\begin{tabular}{lcc} 
& $\begin{array}{c}\text { Share of TVET } \\
\text { Institutions } \\
\text { of TVET } \\
\text { Institutions }\end{array}$ & $\begin{array}{c}\text { Offering Online } \\
\text { Courses } \\
(\%)\end{array}$ \\
\hline Information technology & 114 & 82 \\
\hline Beauty culture & 62 & 69 \\
\hline Automotive and motor mechanics & 85 & 67 \\
\hline Electrical engineering & 83 & 66 \\
\hline Electronics and telecommunications & 72 & 65 \\
\hline Tourism and hospitality & 66 & 64 \\
\hline Metal and light engineering & 35 & 63 \\
\hline Building and construction & 95 & 60 \\
\hline
\end{tabular}

COVID-19 = coronavirus disease, TVET = technical and vocational education and training.

Note: Data are from the 2020 online TVET institutional survey.

Source: Asian Development Bank estimates.

need to have thorough training and open minds for utilizing high-tech solutions. In addition, students missed socializing with peers on campus and they felt there were limited opportunities to develop soft skills through interactions that would be required in the real world of work.

\section{DIGITAL TOOLS AND INTERNET ACCESS FOR ONLINE COURSES}

Online training is being provided largely through low-tech solutions such as social media and e-mails, which reduced the quality of TVET. 
According to the two online surveys, low-tech solutions like social media and e-mail communication were used more than mediumtech solutions such as learning management systems and online collaboration technologies (e.g., Zoom, Microsoft Teams, Skype). The qualitative interviews corroborated this finding. WhatsApp was used extensively among the various social media channels because of its popularity and no cost. WhatsApp was easy to share formal learning contents (such as lecture notes) and to submit assignments. Students could get additional informal learning resources such as YouTube videos and online articles. Some students, however, felt there was information overload, and that it was awkward to ask questions in groups on social media platforms. Moreover, online training requires a high level of self-discipline and motivation. Through audio online training, the instructors also could not read facial expressions whether students understood the content of lectures, and conducting lectures was challenging.

Online collaboration technology tools like Zoom and Google Classroom may be better than social media, but there are challenges utilizing medium-tech solutions for online training. Some of the tools offer a free version but place limitations on time and the number of participants. They also require high technical installation and download storage capacity. In addition to poor internet connection, online training is susceptible to noise and distractions within the household. Plagiarism is also a problem. Even if online collaboration technology tools are available for free, instructors and students have to shoulder the internet connection costs, unlike in higher education institutions where medium-tech solutions such as learning management systems and Zoom are being extensively used - because, as pointed out by Hayashi et al. (2020), university web servers are whitelisted (i.e., could be accessed without internet data charges). If online training continues, financial support needs to be provided to young and visiting instructors receiving limited salaries and to students for internet access and hardware purchases, especially for those who live in remote areas.

Even if online lectures were possible, the instructors had used traditional in-person teaching methods to deliver lectures online. This must change. The two quantitative surveys show that $86 \%$ of instructors had knowledge and experience delivering TVET online, but older instructors were not always equipped with proper know-how for online TVET. The senior instructors were more likely to show a lack of interest and motivation as well as resistance to change. The focus group discussions among students revealed some cases in which instructors simply read lecture notes and did so quickly to cover the topics. During focus group discussions, instructors from DTET suggested that some of them need to be trained as master trainers for each training center so that other instructors across the country could be trained in online TVET pedagogy.

Moving forward, around 60\% of TVET institutions emphasized the need to support equipment purchases and instructor training for online TVET. Without this foundational infrastructure and capacity, it would be difficult to provide existing TVET courses online. Online TVET provides new opportunities for utilizing massive open online courses (MOOCs) for professional training of instructors and even for student course completion through credit transfer of MOOCs or online TVET content created by TVET experts in Sri Lanka. However, for this to occur, essential conditions need to be in place. More than $45 \%$ of TVET institutions supported introducing subsidized student loans or financial aid for students to purchase devices.

While the mindset for blended learning needs to change, instructors are beginning to realize the advantages of saving time and transportation costs, and enhanced flexibility in sharing resources. Instructors stress that blended learning needs to strike a balance between online training, in-person classroom teaching, and practical training, depending on the nature of the subject.

\section{CONCLUSIONS AND RECOMMENDATIONS}

This brief examines the impact of COVID-19 on TVET in Sri Lanka through tracer studies, online surveys, and interviews. The tracer study in November 2020 was conducted by phone to assess labor market impacts on TVET graduates. Two quantitative online surveys were conducted on 21 July-18 August 2020 with TVET institutions and students to understand online training during the pandemic, while seven qualitative interviews were conducted in October 2020 to gauge sentiment on the sudden shift to online TVET courses during the pandemic.

The COVID-19 impact on the labor market resulted in significantly reduced working hours during the first wave in the early stages of the pandemic (March-June 2020). Most TVET graduates could not work at all or could only work less than 5 hours per week during March-June 2020. While working hours had returned to preCOVID-19 levels by the November 2020 tracer study, some TVET graduates lost their jobs or faced reduced incomes, especially those in the tourism and hospitality sector and the self-employed. The job placement rate of TVET graduates in 2020 was $48.2 \%$, a reduction of 2.8 percentage points from 2019 (51.0\%). This reduction, however, might not be entirely attributable to the pandemic because compared with the job placement rate in 2016 (54.5\%), placement has been on a declining trend possibly because of the Easter Sunday attacks in April 2019. Among industries, the tourism and hospitality sector was the hardest hit in terms of employment. Also, the decline in median monthly income was particularly severe for self-employed TVET graduates. Nevertheless, some of the laid-off workers started their own businesses during the pandemic, rather than waiting for wage employment opportunities to come back.

The TVET institutions have made efforts to initiate or expand online training delivery during the pandemic but face many challenges. First and foremost, TVET instructors and students do not always have access to the internet and hardware devices for online training. Second, practical hands-on training is very difficult to provide online. Third, the online platform is far from a student-centered approach because instructors have to provide lecture notes and assignments through social media such as WhatsApp. TVET instructors struggle to deliver online lectures, in contrast to higher education institutions in Sri Lanka where use of online collaboration technology tools such as Zoom has significantly accelerated during the pandemic. 
The TVET instructors also have to repeat lectures once face-toface trainings resume, because not all students could access digital learning during the lockdown.

As a result, the quality of learning is expected to have dropped significantly during the pandemic, although instructors have made notable efforts to keep students learning during COVID-19 rather than being idle at home. According to the online surveys in July-August 2020, 60\%-70\% of major TVET courses continued using low-tech solutions like social media. Among TVET courses, information technology courses achieved more than $80 \%$ uptake. That online TVET was promoted much more during the pandemic than it was pre-COVID-19 might pave the way for new TVET delivery under the "new normal".

Moving forward, it is recommended to provide financial support for TVET instructors and students to enable access to the internet and hardware devices. Professional training for online training delivery is also needed for TVET instructors because they still use the traditional in-person curriculum and pedagogy for online teaching. TVET could also benefit greatly from the use of medium-tech solutions using online collaboration technologies. The new high-tech solutions, such as simulation and virtual laboratories could also enable practical training online (Educause 2020). These high-tech solutions were seldom used during the pandemic and learning outcome needs to be examined in the Sri Lanka context when high-tech solutions are introduced. Due to COVID-19, more TVET graduates may enter the labor market without sufficient practical training. Thus, employers' reactions need to be also examined as a future area of research. Last but certainly not least, the mindset of TVET instructors needs to change and further actions need to be taken to embrace online learning opportunities to realize the "Decade of Skills Development" in 2021-2030.

\section{REFERENCES}

Apedo-Amah, M. C. et al. 2020. Unmasking the Impact of COVID-19 on Businesses: Firm Level Evidence from Across the World. World Bank Policy Research Working Paper. No. 9434. Washington, DC.

Asian Development Bank (ADB). 2016. Performance Evaluation Report. Sri Lanka: Distance Education Modernization Project. Manila. 2018. Tracer Study Sri Lanka: Public Training Institutions in 2016. Manila. 2020a. Asian Development Outlook 2020 Supplement: Paths Diverge in Recovery from the Pandemic. Manila. 2020b. Asian Development Outlook 2020 Update: Wellness in Worrying Times. Manila.

Educause. 2020. Horizon 2020 Report, Teaching and Learning Edition. Louisville, CO.

Government of Sri Lanka. 2019. Sri Lanka Labour Force Survey Annual Report - 2019. Colombo. 2020a. National Policy Framework Vistas of Prosperity and Splendour. Colombo. 2020b. Sri Lanka Labour Force Statistics Quarterly Bulletin: Sri Lanka Labour Force Survey 2nd Quarter 2020. Issue No. 89. Colombo.

Hayashi, R., and Matsuda, N. 2020. COVID-19 Impact on Job Postings: Real-Time Assessment Using Bangladesh and Sri Lanka Online Job Portals. ADB Briefs. No. 135. Manila: ADB.

Hayashi, R. et al. 2020. Online Learning in Sri Lanka's Higher Education Institutions During the COVID-19 Pandemic. ADB Briefs. No. 151. Manila: ADB.

International Labour Organization (ILO). 2021. ILO Monitor: COVID-19 and the World of Work: Updated Estimates and Analysis. 7th ed. Geneva.
About the Asian Development Bank

ADB is committed to achieving a prosperous, inclusive, resilient, and sustainable Asia and the Pacific, while sustaining its efforts to eradicate extreme poverty. Established in 1966, it is owned by 68 members49 from the region. Its main instruments for helping its developing member countries are policy dialogue, loans, equity investments, guarantees, grants, and technical assistance.

ADB Briefs are based on papers or notes prepared by ADB staff and their resource persons. The series is designed to provide concise, nontechnical accounts of policy issues of topical interest, with a view to facilitating informed debate. The Department of Communications administers the series.

Notes:

In this publication, "SLRs" refers to Sri Lanka rupees. ADB recognizes "Ceylon" as Sri Lanka.
The views expressed in this publication are those of the authors and do not necessarily reflect the views and policies of ADB or its Board of Governors or the governments they represent. ADB encourages printing or copying information exclusively for personal and noncommercial use with proper acknowledgment of ADB. Users are restricted from reselling, redistributing, or creating derivative works for commercial purposes without the express, written consent of ADB.

Asian Development Bank

6 ADB Avenue, Mandaluyong City

1550 Metro Manila, Philippines

Tel +63286324444

Fax +63286362444

www.adb.org/publications/series/adb-briefs

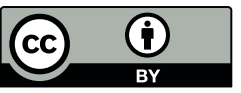

(C) 2021 ADB. The CC license does not apply to non-ADB copyright materials in this publication.

https://www.adb.org/terms-use\#openaccess http://www.adb.org/publications/corrigenda pubsmarketing@adb.org 